\title{
Participação infantil na escola do campo: narrativas produzidas em contexto de pesquisa com crianças
}

\section{Child participation at rural school: narratives produced in the context of research with children}

\section{Participación infantil en la escuela rural: narraciones producidas en contexto de investigación con niños}

\author{
Keylla Rejane Almeida Melo* \\ lara Vieira Guimarães*
}

\section{Resumo}

Este trabalho discute resultados de pesquisa sobre a infância camponesa, realizada com crianças, na perspectiva do protagonismo infantil. Tendo a Sociologia da Infância como arcabouço teórico-metodológico, empreendeu-se uma investigação com narrativas, tecidas em grupos focais com 20 crianças de 8 a 10 anos de idade, em escolas do campo localizadas em duas comunidades rurais do Estado do Piauí. As interações, nos grupos focais, foram desencadeadas a partir de fotografias e desenhos produzidos pelas crianças. Os resultados do estudo revelaram o potencial que as crianças têm para participarem ativamente de instâncias decisórias na escola, pois tecem críticas contundentes à forma como esta instituição está organizada, além de apresentarem sugestões viáveis ao aprimoramento das práticas pedagógicas que se realizam em seu interior. Conclui-se que é urgente o reposicionamento das crianças no âmbito escolar, como sujeitos que possuem experiências, pensam e contribuem para a (re)construção do ambiente educativo, como sujeitos de direitos, aptos à participação social.

Palavras-chave: Educação do Campo. Sociologia da Infância. Práticas Pedagógicas. Direito à Educação. Protagonismo Infantil.

Recebido em 09/10/2019 - Aprovado em 04/02/2020

http://dx.doi.org/10.5335/rep.v27i2.11441

Doutora em Educação (2019) pela Universidade Federal de Uberlândia (UFU). Professora da Universidade Federal do Piauí. Membro do Núcleo de Estudos, Pesquisa e Extensão em Educação do Campo - Nupecampo (UFPI) e do Grupo de Estudos e Pesquisas em História e Geografia - GEPEGH (UFU), Brasil. Orcid: https://orcid.org/0000-0003-3818-5955. E-mail: keyllamelo@ufpi.edu.br

** Doutora em Educação pela Universidade de São Paulo. Pós doutorado na Universidade Federal Fluminense. Professora Associada da Faculdade de Educação e do PPGEDU da Universidade Federal de Uberlândia (UFU). Integra a coordenação do Grupo de Pesquisa Formação Docente, Saberes e Práticas de Ensino de História e Geografia - GEPEGH, da UFU, Brasil. Orcid: https://orcid.org/0000-0002-5509-8805. E-mail: iaravgm@gmail.com 


\section{Abstract}

This paper discusses results of research on peasant childhood, conducted with children, from the perspective of child protagonism. Having the Childhood Sociology as a theoretical-methodological framework, an investigation was conducted with narratives, woven in focus groups with 20 children from 8 to 10 years old, in rural schools located in two rural communities of the State of Piauí. The interactions in the focus groups were triggered from photographs and drawings produced by the children. The results of the study revealed the potential that children have to actively participate in decision-making bodies at school, as they give scathing criticism to the way this institution is organized, besides offering viable suggestions for improving the pedagogical practices that take place within them. It is concluded that the repositioning of children in the school environment is urgent as subjects who have experiences, think and contribute to the (re) construction of the educational environment, as subjects of rights, able to social participation.

Keywords: Rural Education. Childhood Sociology. Pedagogical Practices. Right to Education. Child Protagonism.

\section{Resumen}

Este artículo discute los resultados de la investigación sobre la infancia campesina, realizada con niños, desde la perspectiva del protagonismo infantil. Teniendo la Sociología de la Infancia como marco teórico-metodológico, se realizó una investigación con narraciones, tejidas en grupos focales con 20 niños de 8 a 10 años de edad, en escuelas rurales ubicadas en dos comunidades rurales en el estado de Piauí. Las interacciones en los grupos focales se desencadenaron a partir de fotografías y dibujos producidos por los niños. Los resultados del estudio revelaron el potencial que los niños tienen para participar activamente en los órganos de toma de decisiones en la escuela, ya que hacen críticas convincentes sobre la forma en que esta institución está organizada y presentan sugerencias viables para mejorar las prácticas pedagógicas que se realizan em su interior. Se concluye que es urgente el reposicionamiento de los niños en el entorno escolar, como sujetos que tienen experiencias, piensan y contribuyen en la (re)construcción del entorno educativo, como sujetos de derechos, capaces de participación social.

Palabras clave: Educación rural. Sociología de la infancia. Prácticas pedagógicas. Derecho a la Educación. Protagonismo infantil.

\section{Introdução}

A escola é um tempo/espaço que abarca uma boa parte do cotidiano das crianças, definindo muitas vezes sua vida, em função de suas formas de organização. É como se a escola fosse a atividade central a partir da qual se organizam as outras atividades infantis. Assim, é importante que a forma de organização desse tempo/ espaço seja, cuidadosamente, pensada de modo a contribuir, efetivamente, no processo de aprendizagem e desenvolvimento das crianças.

Acreditamos que essa organização não é tarefa apenas de adultos que se dedicam a concebê-lo para as crianças sem, no entanto, reconhecer que essas apresentam plena capacidade para pensar e elaborar projetos. Trazer à tona as singularidades infantis, considerando as potencialidades e limitações próprias da categoria geracional a que pertencem, se mostra fundamental, pois a vida das crianças deve 
se desenvolver num contexto de participação ativa, visto que diversos estudos e pesquisas já comprovaram a afeição da criança à participação social, e a legislação reconhece o seu caráter político, ao defini-la como sujeito de direitos.

Este trabalho tem como objetivo discutir os sentidos produzidos por crianças camponesas sobre a escola do campo, demonstrando o potencial que possuem para analisar o contexto institucional, apontar contradições e propor estratégias de melhoria das práticas que nele se desenvolvem. Sentidos produzidos em pesquisa com 20 crianças, na faixa etária de 8 a 10 anos de idade, à luz dos referenciais teórico-metodológicos da Sociologia da Infância. Optamos pelas narrativas como método de investigação, que foram tecidas em grupos focais, realizados em duas escolas localizadas em comunidades rurais do centro-norte piauiense.

Para a feitura deste trabalho, dialogamos com estudiosos que se inserem na vertente da Sociologia da Infância (GOUVÊA, 2011; HENDRICK, 2005; QVORTRUP, 2010; SARMENTO, 2011a, 2011b, 2005, 2003) e da Educação do Campo (CALDART, 2015), com o intuito de olhar a escola como instituição de educação formal das crianças, sobretudo das classes populares, que foram mais tardiamente atendidas, como as crianças do campo. Tal entendimento nos remete à ideia de que é necessária e possível uma organização dessa instituição para atender às singularidades do contexto campesino, de modo a oferecer às crianças efetiva aprendizagem para uma formação humana, levando-se em conta a potência que têm esses sujeitos para participarem de decisões relacionadas a questões que lhes digam respeito, pois são sujeitos de experiências, mesmo antes de seu ingresso na escola. Por isso, precisam ser melhor compreendidas e aceitas no cotidiano escolar.

\section{A escola como espaço/tempo de institucionalização da infância}

Como processo dialético de formação humana, a Educação do Campo conduz ao desvelamento da realidade, fazendo emergir as contradições existentes de modo que possamos compreender a trajetória histórica de constituição do que se coloca como real. Olhar a escola numa perspectiva de construção histórico-social ajuda-nos a compreender que outras formas de organização desse espaço/tempo são possíveis e viáveis. Por isso, é controversa a lógica de naturalização da escola e de suas práticas, pois subtrai aos sujeitos da educação (alunos, docentes, famílias) o poder de escolha, de criação, de transformação, o que cristaliza práticas, posturas e ações.

A Sociologia da Infância também lança um olhar crítico sobre a escola, sobretudo a escola pública, como espaço institucional, por excelência, de pertença 
das crianças, "criada no final do século XVIII e cuja frequência obrigatória se institucionalizou a partir da $1^{\mathrm{a}}$ metade do século XIX, tendo a escolaridade generalizada, alargada e estendida desde então, ininterruptamente" (SARMENTO, 2011a, p. 586). É importante que compreendamos a invenção da escola, nos moldes como ela se apresenta hoje, como lugar e tempo privilegiado de socialização e formação das gerações mais novas. Essa compreensão leva-nos a romper com uma visão da escola como instituição universal e neutra, de existência necessária e independente da vontade humana, tão naturalizada a ponto de ser impensável a sua não existência.

As condições históricas que determinaram a necessidade de existência da escola que, nos seus primórdios, na Grécia, é direcionada a atender a uma parcela muito reduzida e privilegiada da população, expandiram-se na modernidade, tornando-a instituição de passagem obrigatória também das classes populares, a partir da reivindicação da escola como direito público, gratuito e laico.

Varela e Alvarez-Uria (1992), no texto A maquinaria escolar, ao analisarem as determinações das condições históricas de existência da escola no interior de nossa formação social, mostram que desde o século XVI tais condições vinham emergindo, com destaque para a Igreja Católica como a precursora na instalação do sentimento de infância inocente. Os autores destacam a instituição de diferentes infâncias no bojo da sociedade de classes: a infância angélica e nobilíssima do Príncipe, a infância de qualidade dos filhos das classes distinguidas e a infância rude das classes populares. A cada uma delas, uma atenção educacional diferenciada por parte dos educadores católicos.

A função que a escola ocupa socialmente está diretamente relacionada ao tipo de sociedade que se pretende construir ou manter. São, portanto, as crises que se instalam dentro de uma sociedade, a partir das lutas de classes e pelo poder, que levam ao repensar e à, consequente, reestruturação das instituições sociais, como a escola. "Na Época Moderna, com a crescente utilização dos códigos formais, houve a exigência de que a população tivesse domínio de cultura intelectual, cujo componente elementar era a leitura e a escrita, o que provocou a pressão social pela escola e a necessidade de sua expansão" (RAMOS; LEITE; FILGUEIRAS FILHO, 2012, s/p). Assim, instituiu-se o privilégio do Estado no campo da educação escolar.

Os estudos de Gondra (2018, p. 21) esclarecem que a emergência de consolidação do Estado Nacional brasileiro no século XIX trouxe consigo a necessidade de construção do sistema educacional, sendo instaurados muitos dispositivos de controle, de modo a alcançar um modelo de escola menos arcaico e mais profis- 
sionalizado, buscando produzir "uma estrutura cada vez mais hierarquizada, por meio de uma forte ramificação do poder", levando os administradores do Estado a culparem os professores pelo fracasso da educação. Em relação aos saberes e modos de transmissão às crianças, o que vigorou, nesta época, foi uma perspectiva cientificista, que, como afirma Gouvêa (2011, p. 557, grifo da autora), "uma menorização da imaginação e mesmo a negação de sua importância na construção do conhecimento. Toda uma pedagogia foi edificada na crítica ao uso da imaginação no trabalho pedagógico com a criança". Portanto, um aspecto universal do ser criança foi negligenciado na sua formação.

Sarmento (2011a, p. 588) ressalta que a escola, historicamente, tem se ocupado mais do aluno do que da criança, pois desconsidera seus "saberes e emoções, aspirações, sentimentos e vontades próprias, para dar lugar ao aprendiz, destinatário da acção adulta, agente de comportamentos prescritos, pelo qual é avaliado, premiado ou sancionado". Desde a primazia da pedagogia católica, sistematizada pelo Ratio Studiorum, que se busca a fabricação de um modelo de comportamento infantil aceitável socialmente, isto é, educado para se tornar um sujeito governado pelo sistema, pelas regras e pelos docentes.

Desse modo, a ação do Estado vai se ampliando sobre o governo de uma parcela da população, por meio da escola, definindo quem são os sujeitos dessa instituição, o que devem aprender, como devem agir, os modos de ensinar, a qualificação dos quadros do magistério, além de "regulamentar o raio de atuação da própria escola, adotando um critério baseado na demanda, com base no estatuto de freguesia, paróquia ou curato, delineando, assim, uma geografia desigual da instrução" (GONDRA, 2018, p. 16).

É nítida, portanto, a histórica exclusão dos povos do campo do processo de escolarização na sociedade brasileira, pois às populações dispersas ou era negado o acesso à escola ou era oferecida uma escola de qualidade inferior às das vilas. Se pensarmos na situação da menina pobre, residente no campo, as oportunidades de escolarização eram ainda mais raras no Brasil colônia. No capitalismo, a condição de exclusão desses povos é reforçada, já que o parâmetro hegemônico é dado pelo urbano, que é a marca da modernidade. Nesse ínterim, o campo, concebido como espaço de produção, e não de vida humana, ou de vidas que pouco interessam, não se constitui como prioridade em termos de escolarização, num projeto de sociedade "civilizada", como o que se propunha no período imperial.

Nesse sentido, a Educação do Campo (EdoC), constituída no final da década de 1990, vem se consolidando "como uma articulação nacional das lutas dos 
trabalhadores do campo pelo direito à educação, materializando ações de disputa pela formulação de políticas públicas no interior da política educacional brasileira" (CALDART, 2015, p. 1-2).

O processo de redemocratização do Brasil, na década de 1980, resultou na aprovação da Constituição de 1988, que determinou que o acesso ao ensino obrigatório e gratuito é direito público subjetivo. Esse processo foi decisivo para o fortalecimento das lutas dos movimentos sociais, inclusive para a garantia de reivindicações atendidas pela nova Lei de Diretrizes e Bases da Educação Nacional (LDB), instituída em 1996, que dentre as conquistas, destacamos o que define o Art. 28 no que tange à oferta de educação básica para a população do campo, determinando que sejam promovidas as adaptações necessárias, considerando-se as peculiaridades da vida rural, especialmente em relação aos conteúdos curriculares e metodologias; à organização escolar, com calendário escolar que considere as fases do ciclo agrícola e as condições climáticas; “à adequação à natureza do trabalho na zona rural" (BRASIL, 1996).

"A escola, enquanto instituição construída socialmente para realizar a formação humana nas diferentes temporalidades de vida, se tornou, no movimento histórico, dever do Estado e direito do cidadão" (RAMOS; LEITE; FILGUEIRAS FILHO, 2012, s/p). Contudo, as dificuldades têm se dado na materialização da legislação que assegura esse dispositivo constitucional. Em relação ao Art. 28 da LDB, por exemplo, supracitado, a realidade tem mostrado que, mesmo localizadas em contexto rural, as escolas do campo não têm promovido práticas educativas e pedagógicas centradas nas peculiaridades da vida no campo, apesar das determinações legais, pois ainda são escassas as políticas públicas que permitam transpor as conquistas do plano jurídico para o real. Assim, pressões dos Movimentos Sociais do Campo são traduzidas em textos legais, mas pouco materializadas no dia-a-dia da escola, a começar pela padronização do tempo escolar, com calendário letivo igual ao da zona urbana, mesmo a legislação determinando a consideração dos ciclos agrícolas.

Pelo exposto, é possível afirmar que, historicamente, não há neutralidade nem universalidade na educação institucionalizada. No caso brasileiro, a escola sempre foi calcada na separação entre trabalho intelectual e trabalho manual, apesar da expansão do acesso à escola às camadas populares, preparando-as para as atividades pouco valorizadas socialmente. Uma escola que inclui a garantia da presença da criança no espaço escolar, mas que continua excluindo os mais pobres por não oferecer uma escola de qualidade para todos. 
Temos a configuração de um modelo dual de escola: uma destinada aos filhos da classe burguesa e outra aos filhos dos trabalhadores, com objetivos diferentes, mas com a disseminação de conhecimentos legitimados por essa classe. Sarmento, em entrevista a Delgado e Muller (2006, p. 21), destaca os efeitos geracionais nefastos "do sistema dual educativo brasileiro (público para os pobres, privado para as classes médias e altas)".

A transformação histórica da escola nos leva a perceber que essa instituição serve para legitimar um tipo de sociedade que é sustentada a partir da formação de um modelo de ser humano para nela atuar. No contexto da modernidade, foi concebida com o objetivo de atender a um conjunto de demandas específicas do projeto histórico que a planejou e procurou pô-la em prática: educar todos os cidadãos, alfabetizar cada habitante no uso correto do seu idioma pátrio, ensinar a fazer cálculos e incutir certos valores e normas, isto é, disciplina como humanização (SIBILIA, 2012). Contudo, no caso brasileiro, isso não se efetivou e os mais pobres continuam expropriados de saberes básicos por conta dos problemas enfrentados pelas escolas.

A escola escolhe o que, como e quando ensinar, com base em intenções que nem sempre são conscientes para todos os atores que nela atuam. Sarmento (2011a, p. 588) afirma: "Com a escola, a criança assume o estatuto de ser social, objecto de um processo intencional de transmissão de valores e saberes comuns, politicamente definidos, e destinatário objectivo de políticas públicas”. Contudo, nada garante que a presença da criança na escola seja consubstanciada por uma formação de qualidade, fruto de políticas públicas consequentes e tampouco executadas de forma a garantir os direitos anunciados na legislação.

Assim, a escola acaba por não ajudar a transpor a segregação social que marca historicamente a sociedade brasileira. Apesar de estar alicerçada em discurso jurídico de igualdade e equidade, não consegue afetar as enormes barreiras que os mais pobres enfrentam no processo de mobilidade social, nem consegue atuar de forma incisiva na indigna concentração de renda e nas desigualdades sociais do país.

O processo de institucionalização da infância é crescente no Brasil, com a presença das crianças nas instituições escolares sendo concretizada em termos numéricos, mas em relação à qualidade, é preciso questionar. Há dados positivos dessa institucionalização, assim como há contradições. A Sociologia da Infância ajuda-nos a compreender esse processo, "que promoveu, progressivamente, um conjunto de exclusões das crianças do espaço-tempo da vida em sociedade" (SARMENTO, 2005, p. 368). O autor destaca uma negatividade constituinte na institucionalização da 
infância, que prevalece no disciplinamento das crianças no contexto das escolas, isto é, há uma "interdição simbólica de pensar as crianças a partir da positividade das suas ideias, representações, práticas e acções sociais" (SARMENTO, 2005, p. 368). O pensamento infantil não é visto pelos adultos como pensamento distinto, mas como ilegítimo, incompetente, impróprio e inadequado e isso acabou sendo reproduzido na escola.

Cumpre-nos destacar a importância inegável de visibilização social das crianças na modernidade, destinando-lhes um lugar social próprio, sendo decisiva a criação da escola para a construção social do estatuto da infância. No entanto, o que questionamos são as formas de controle e dominação que assujeitam as crianças e lhes tiram a possibilidade de se constituírem como sujeitos sociais. Hendrick (2005, p. 38) destaca ser importante a consciência que temos hoje das crianças como atores sociais, mas ainda prevalece, entre adultos, inclusive professores, a concepção modernista de criança como ser frágil, carente, sem desejo, sem experiência. "Sempre se faz para as crianças e não com elas".

Esta não é a perspectiva que deveria estar em voga a partir da legislação que instituiu como direito da criança, o direito à participação. Nesse sentido, Sarmento, em entrevista a Delgado e Muller (2006), leva-nos a refletir, a partir de pressupostos da Sociologia da Infância, a possibilidade de construção de uma escola embasada em uma proposta crítica de promoção e estímulo aos direitos das crianças. $\mathrm{O}$ autor propõe estudar "a criança antes do aluno e a interação social inter e intrageracional antes da instituição", considerando que "o aluno é institucionalmente investido sobre um ser social concreto, a criança, cuja natureza biopsicossocial é incomensuravelmente mais complexa do que o estatuto que adquire quando entra na escola" (DELGADO; MULLER, 2006, p. 17).

É fundamental que a escola se ocupe da criança e não apenas do aluno; que assista a ela com base nas suas necessidades e potencialidades do presente e não como cidadão do futuro. Com base nessa concepção de criança como um vir a ser, como alguém que ainda não se configura como cidadão pleno, a natureza lúdica, imaginativa, interativa, coletiva, das crianças tem sido um aspecto negligenciado pela escola, pelo próprio modelo organizacional adotado, inspirado em certos aspectos nas fábricas (SARMENTO, 2011a).

É possível compreender o percurso histórico-social, não livre de conflitos e rupturas, que permitiu a instalação da escola como instituição que foi se estruturando para contribuir na conformação de modelos sociais. No entanto, Lefebvre (apud TELLEZ, 2017) assevera que, apesar de o espaço ser socialmente produzido e his- 
toricamente determinado pelo capital, o espaço escolar é uma espécie de potência criadora e subversiva na produção do espaço cotidiano, por seu dinamismo social. No espaço, os grupos sociais se reinventam e produzem outras configurações, nem sempre confluentes com os interesses dos atores hegemônicos. Isso nos anima para a resistência e para a luta pela transformação da escola, acreditando que esse espaço se transforma constantemente.

Reconhecer a criança como ator social significa estabelecer outras pretensões, exigências e desejos para a escola, de modo geral, e para as práticas docentes, de modo particular. O modelo pedagógico fundamentado nos preceitos da pedagogia da transmissão já não dá conta da infância contemporânea. Oliveira-Formosinho (2007, p. 13) lembra-nos que temos "uma herança rica e diversificada de pensar a criança como ser participante, e não como um ser em espera de participação". No entanto, a pedagogia transmissiva persiste, ignorando um fazer pedagógico que leve em conta a criança como sujeito de direitos, competente e apta a ter espaço de participação. Retomar essa herança pedagógica pode ser um caminho para a construção de experiências mais mobilizadoras para as crianças e também para os docentes.

\section{Metodologia}

Fundamentada em pressupostos teórico-metodológicos da Sociologia da Infância, a pesquisa foi orientada por uma concepção de criança como ator social, possuidora de experiências, desejos, pontos de vista, que as torna com capacidade de participação social. Dessa forma, foi imperativo optarmos por um processo investigativo tendo as crianças como coparticipantes, coprodutoras de dados para a consecução do objetivo de pesquisa.

Assim, optamos por utilizar a pesquisa com narrativas, entendendo-a como uma forma de compreensão da experiência vivida que, ao ser narrada, permite uma rede de interações entre pesquisadora e participantes, produzindo sentidos sobre o mundo, as pessoas, os lugares. Como afirmam Clandinin e Connelly (2015, p. 51): "É um tipo de colaboração entre pesquisador e participantes, ao longo de um tempo, em um lugar ou série de lugares, e em interação".

Essa interação se deu por meio de grupos focais, num contexto muito específico de vivência das crianças: a escola, por um período de tempo que possibilitou o estabelecimento de vínculos de confiança, necessários ao desencadeamento das narrativas. Grupo focal é entendido aqui como "um conjunto de pessoas selecionadas e reunidas por pesquisadores para discutir e comentar um tema, que é objeto 
de pesquisa, a partir de sua experiência pessoal" (POWEL E SINGLE, 1994 apud GATTI, 2005, p. 7). Considerando o caráter lúdico, imaginativo, criativo das crianças, utilizamos, como dispositivos desencadeadores das interlocuções, fotografias e desenhos, produzidos por elas, de espaços institucionais que lhes despertavam afetos. Esses dispositivos, apesar de importantes no processo de produção dos dados, não foram considerados nas análises, sendo o foco apenas as falas das crianças.

Como contextos empíricos foram selecionadas duas escolas localizadas na zona rural de municípios piauienses, denominadas, neste trabalho, de Escola A e Escola B. Em cada uma, foi formado um grupo focal com 10 crianças, de 8 a 10 anos de idade, selecionadas a partir da adesão voluntária destas. Essa faixa etária foi escolhida pelo fato de considerarmos que, nesta etapa do seu desenvolvimento, as crianças já conseguem expressar melhor suas experiências.

Em pesquisa com crianças, o cuidado ético tem uma dimensão especial, por isso, as crianças e suas famílias foram informadas sobre detalhes da pesquisa, inclusive sobre a condição de anonimato dos participantes na divulgação dos resultados. No texto, foram utilizados nomes fictícios para as crianças e para os sujeitos por elas citados em seus relatos. Para tanto, cada pai ou responsável assinou um Termo de Consentimento Livre e Esclarecido, e cada criança interlocutora assinou um Termo de Assentimento para participar da pesquisa.

Os dados foram organizados em eixos temáticos, definidos com base nas interações, destacando-se não somente as opiniões majoritárias, mas também as que ficaram em minoria. Todo o material coletado (transcrições, registros em diários de pesquisa) foi compatibilizado de modo que o conjunto dos relatos fosse o mais completo possível. Ancorados em Gatti (2005), construímos planos descritivos das falas, dividindo-os por contexto empírico, destacando as semelhanças e diferenças entre os relatos, e agrupando-os em função dos sentidos percebidos.

\section{Os sentidos produzidos pelas crianças camponesas sobre a escola}

A partir da discussão da escola como espaço privilegiado de institucionalização da infância, passamos a discutir a instituição escolar situada no campo, tendo como mote as perspectivas das crianças interlocutoras sobre este espaço/tempo de ensino e aprendizagem, depreendidas por meio de suas narrativas nos grupos focais. Como seres de experiência, ao refletirem sobre a escola, as crianças narraram histórias, teceram pontos de vista e construíram novos entendimentos de si e do mundo. 
Muitos afetos, risos, brincadeiras foram compartilhados nas seções de grupos focais sobre a escola, quando narravam acontecimentos marcantes das trajetórias escolares. Porém, também fizeram denúncias, demonstraram indignação e repulsa diante de algumas situações que relataram. Além disso, teceram sugestões de mudanças que poderiam aprimorar a organização da escola. A seguir, analisamos cada um dos eixos temáticos.

\section{Infraestrutura física de escolas do campo}

As duas escolas possuem prédio escolar próprio, que possibilitam condições aceitáveis de funcionamento. Os únicos espaços existentes para recreação e lazer são o pátio e o campo de futebol. O primeiro não foi escolhido por nenhuma criança para ser fotografado, talvez porque sua função como local de socialização, encontro, diversão não esteja sendo desempenhada. Durante o tempo em que permanecemos nas duas escolas, esse espaço funcionou apenas como uma espécie de refeitório. Já o campo de futebol foi um espaço em que todas as crianças das duas escolas dirigiram afeto positivo, mesmo reconhecendo a necessidade de melhorias nas estruturas existentes.

O campo de futebol da Escola A foi escolhido por três duplas de crianças, mas, quando perguntamos quem gosta do local, todas as crianças levantaram a mão e gritaram: “-Eu!". Na verdade, o campo de futebol dessa escola, é um espaço improvisado, organizado durante a execução de um projeto de Educação Ambiental que reciclou pneus, transformando-os em item de decoração, de delimitação de espaços. Mesmo assim, as crianças atribuem a esse local improvisado uma grande importância no contexto escolar, pois representa o lúdico, a liberdade, a brincadeira, a possibilidade de socialização com os outros. É o espaço onde podem vivenciar situações típicas da infância (correr, brincar, jogar bola, movimentar o corpo livremente). Porém, elas fazem uma análise muito crítica do lugar, apontando diversas problemáticas, bem como destacam possibilidades de melhoria. Uma criança cita, por exemplo, a necessidade de construir uma quadra.

O mesmo pode ser dito em relação ao campinho da Escola B, que se assemelha mais a um campo de futebol, mas também apresenta diversos problemas apontados pelas crianças, mesmo sendo um lugar de afeto positivo para todas elas. Em seus posicionamentos, as crianças consideram diversos aspectos para aprimorar o espaço que já existe, embora uma criança fale da possibilidade de construção de uma quadra em outro terreno. Há concordâncias, discordâncias, complementações 
a ideias dos outros, mas, em síntese, desejam um espaço melhor estruturado, mais amplo, com telas que impeçam a bola de sair, com cobertura que as abrigue do sol, possibilitando sua utilização em qualquer momento do dia.

O campo de futebol representa, para as crianças, a materialização da peculiaridade do ser criança. Apesar dos problemas apontados, é um espaço pelo qual nutrem grande afeto, o que pode ser visivelmente constatado pelo trecho de anotação escrito e lido pela Flávia (10) no momento em que analisávamos as fotografias do campo de futebol: “- O campo é legal porque a gente pratica coisas novas e faz a gente se sentir bem. Quando eu entro nesse campo eu sinto uma coisa tão legal dentro de mim, eu não sei nem explicar”.

Passeggi, Nascimento e Oliveira (2016), em pesquisa narrativa realizada com crianças da zona rural, explicitam que a educação no meio rural reflete o que há de mais rudimentar no que se refere ao tratamento dado à educação no Brasil. Sem deixarem de reconhecer que essa é uma situação que aflige a educação brasileira de forma geral, as autoras reconhecem que a precariedade é preponderante nas áreas rurais. Vemos, pelos diálogos com as crianças, a importância atribuída por elas a uma quadra de futebol na escola. E, mesmo sendo uma construção cujos custos não são altos, não se configura como um investimento prioritário do poder público, o que faz com que a própria escola, com parceria de voluntários, alunos, famílias, improvisem espaços para a prática de esportes.

As crianças, em suas narrativas, trouxeram evidências dessa precariedade histórica a qual estão submetidas as escolas do campo brasileiro. A infraestrutura física insuficiente para dar conta de todas as atividades que precisam ser desenvolvidas na/pela escola agrava-se com a falta de manutenção adequada dos espaços. Em suas análises pormenorizadas sobre mais um espaço improvisado na Escola A: local onde armazenam o lixo, as crianças denunciaram a precariedade das instalações, a ausência de um espaço específico com tal finalidade, as questões de higiene, promoção da saúde. É apontada a possibilidade de construção de um espaço próprio e outras formas de organizar esse armazenamento, apesar da ausência desse espaço.

Em pesquisa realizada sobre a oferta e demanda de Educação Infantil no campo, Leal e Ramos (2012, p. 174) constataram problemas enfrentados pelas escolas com relação ao armazenamento e coleta do lixo, que não ocorrem de maneira regular, destacando que tais problemas, além de interferirem no funcionamento das escolas e afetarem as condições de higiene e saúde, também "parecem se relacionar a uma questão mais ampla: a ainda insuficiente atuação do poder público no que 
diz respeito a políticas que assegurem a infraestrutura para a sobrevivência das populações do campo". Notadamente, a precariedade não se resume ao contexto escolar, mas é generalizada ao contexto comunitário.

As autoras citadas ainda destacam situações diversas quanto à infraestrutura dos prédios. Concluindo que, "na maioria dos municípios, as escolas necessitam de reformas, com ampliação dos espaços, substituição de portas e janelas, além de reparos de piso e teto, e pintura" (LEAL; RAMOS, 2012, p. 173-174). As crianças da Escola B descrevem bem essa situação, conforme descrito no excerto a seguir:

Marina (10): - As portas têm as fechaduras esculhambadas.

Raíssa (9): - Uma vez eu, a Marina e vários alunos ficamos trancados na sala. O coordenador fechou a porta e ela não abriu mais.

Ravi (9): - Foi. Aí precisou abrir com uma tesoura. A Ana Clara também trancou a gente. Ela não sabia que a porta não abria, aí foi preciso chamar o diretor.

Raíssa (9): - E um dia desses nós ficamos trancados nessa outra sala bem aí.

Mediadora: E por que não pularam as janelas?

Raíssa (9): - Ah, porque nas salas não tem janelas.

Kelly (8): - Se tivesse janelas, era só pular. Mas não têm... Seria bom se tivesse.

As narrativas das crianças evidenciam uma situação que se estende há algum tempo na escola, por falta de manutenção nas instalações do prédio. Outro aspecto a ser ressaltado é a ausência de janelas nas salas, que nos leva a constatar que os projetos arquitetônicos dos prédios não se coadunam com as necessidades pedagógicas das escolas. Janelas é um item essencial nesses projetos, tendo em vista a necessidade de contato visual das crianças com o mundo exterior e mesmo pela importância de se ter um espaço iluminado pela luz solar, arejado, ventilado. No caso específico do problema das fechaduras das portas, ter janelas nas salas resolveria em parte a dificuldade de abrir a sala em caso de ter pessoas trancadas.

Diversos outros problemas foram apontados pelas crianças na infraestrutura das escolas, como banheiros pequenos, com chuveiros e vasos sanitários disputando o mesmo espaço; vasos sanitários e pias que não funcionam e não se adequam à altura das crianças da educação infantil. Os banheiros são um elemento do espaço escolar que muito evidencia essa precariedade, por falta de manutenção nas instalações. Além da ausência de banheiros adequados, as crianças apontam a falta de espaços como biblioteca, salas de leitura e jogos, piscina, parquinho; muito mato ao redor das escolas e insuficiência de árvores; pisos quebrados; calçadas altas 
e estreitas; muro rachado, prestes a cair; vidros das janelas quebrados; paredes sujas; jardins sem a devida proteção das plantas, ocasionando situações de tristeza nas crianças ao verem tais plantas pisadas, arrancadas, como aconteceu com um espaço escolar muito apreciado pelas crianças da Escola A: a horta.

A horta foi um espaço organizado durante a execução de um projeto de extensão na escola, sendo criado e organizado com a participação efetiva das crianças, por isso, é um espaço que lhes desperta afeição. Elas reconhecem a importância de a escola ter uma horta, já que esta oportuniza a produção de alimentos saudáveis, reduzindo, inclusive, gastos para a escola.

Consideramos a horta um espaço importante, sobretudo no contexto das escolas do campo, por contemplar especificidades do modus vivendi das populações camponesas e, portanto, fortalecer a identidade do homem do campo. Na perspectiva teórico-metodológica da Educação do Campo, possibilita a materialização de alguns dos seus princípios, como a integração educação-trabalho, articulação teoria-prática, aproximação entre conhecimentos escolares e saberes da cultura camponesa. Em torno da horta, portanto, várias possiblidades pedagógicas, enfatizadas pela Educação do Campo, podem ser ressaltadas: fortalecimento da identidade camponesa, contextualização do ensino-aprendizagem, materialização de princípios da Educação do Campo e da Educação Ambiental, adoção de hábitos alimentares saudáveis desde a infância, além do despertar um senso de responsabilidade e cooperação na escola, que se estende para o fortalecimento dos vínculos entre família, comunidade e escola.

\section{Organização do ambiente educativo}

A organização dos espaços e materiais está diretamente relacionada à infraestrutura, pois cada espaço existente na escola é potencializado pela forma como é organizado, que se pretende que se leve em conta a intencionalidade educativa, voltada para proporcionar a vivência de experiências múltiplas. As crianças da Escola A pensaram a organização da escola desde a entrada do prédio, incrementando-a com itens da natureza, como flores e árvores. Em muitos desenhos da escola, as árvores ocupam espaço central, junto com outros elementos, no cenário imaginado.

Algumas crianças disseram ser importante que na escola tenha mais árvores, porque "enfeitam", "dá mais ar e sombra", "ficaria mais frio por causa da sombra" e "poderia ter umas árvores que dão flores". Esse aspecto, que se refere a um ambiente bonito, limpo, colorido, florido, arborizado, arejado, foi reiterado diversas 
vezes pelas crianças, tanto que esses espaços livres, com áreas verdes, foram os mais fotografados. Esses são espaços que as crianças demonstram apreciar, porém, ao conversarem sobre eles, sempre sugeriam mudanças que os qualificariam, na visão delas.

As crianças prezam pelos detalhes, podendo contribuir em grande medida com a organização dos espaços institucionais. Os adultos, com o olhar automatizado, diminuem/perdem o senso de organização pelo excesso de atividades a que estão submetidos, podendo ser auxiliados pelas contribuições criativas das crianças. Como explica Sarmento (2011b, p. 44), esse processo criativo das crianças é também reprodutivo, "isto é, nele se presentifica um passado histórico culturalmente sedimentado e a inovação sempre inerente a toda a acção humana".

As experiências vivenciadas pelas crianças aprimoram esse processo criativo, como podemos verificar nas falas de Tadeu (8) sobre o reaproveitamento da água utilizada para aguar as plantas, tendo em vista ter participado de ações de Educação Ambiental em projetos de extensão, sendo esta estratégia de reaproveitamento uma das realizadas em parceria com as crianças: Tadeu (8): “- Eles podiam mudar a caixa d'água de lugar, para onde ela estava antes e só instalar um cano para levar a água para o lugar onde as mulheres lavam as coisas. Fazer que nem fizeram com o bebedouro". Ao que a Mediadora pergunta: “- Mudaram o bebedouro de lugar?”. E ele responde: “- Não. Eles instalaram um cano e toda vez que derrama água, eles aproveitam e ela vai para um pezinho de planta".

O cuidado com a organização do ambiente educativo constitui-se importante dimensão da qualidade da educação oferecida às crianças. Conforme estudos de Silva e Luz (2012, p. 189), a configuração desses ambientes "pode favorecer ou desfavorecer o sentimento de segurança, o desenvolvimento da autonomia das crianças, valorizando suas práticas e as interações criança-criança e entre as crianças e os adultos".

É importante planejar pedagogicamente a organização dos espaços e materiais visando à construção de um ambiente efetivamente educativo na escola. A disponibilidade dos espaços e dos materiais interferem diretamente na riqueza ou na escassez desse ambiente. Na pesquisa já citada, Leal e Ramos (2012, p. 174) constatam que a maioria das escolas pesquisadas não possui mobiliário adequado às crianças de 0 a 6 anos nem livros de literatura infantil, brinquedos, etc. "Dessa forma, a ausência desses equipamentos apropriados não favorece um trabalho pedagógico que permita, à criança, o seu desenvolvimento integral”. 
As crianças da Escola B deixam transparecer incômodo em relação à desorganização dos espaços e materiais existentes. Inclusive, pensam num tipo de ambiente educativo que assista melhor às crianças da educação infantil, com espaços, materiais, tempos diferenciados. Em diversos momentos do grupo focal, elas traziam a necessidade de organização do espaço da sala onde trabalhávamos. Compreendem que o ambiente educativo bem elaborado é condição para o bom funcionamento da escola. Horn (2004 apud SILVA e LUZ, 2012, p. 189) pontua: "Os espaços integram a dimensão pedagógica da escola, e sua adequação relaciona-se com as possibilidades que ele oferece de ser transformado, de modo a proporcionar os meios para as experiências de crianças e adultos”. Em suas narrativas, as crianças parecem compreender bem a dimensão pedagógica da escola. Elas fazem críticas a materiais guardados, à dificuldade de acesso a eles, e à desorganização de espaços e materiais.

A partir das interlocuções das crianças, diversas questões podem ser discutidas, como: 1) a consciência que têm as crianças de que está lhes sendo negado o acesso a materiais que estão na escola para uso pedagógico e, no entanto, permanecem encaixotados ou à vista, mas indisponíveis para elas. A observação da Marina (10) esclarece: “- Não adianta ter os livros e a biblioteca e não poder pegar os livros"; 2) a necessidade de organizar os materiais, pois da forma como estão, seja guardados ou expostos, não podem permanecer. Como observa Kelly (8): “- Olha bem aqui essa prateleira, toda horrível!"; 3) os gestores não investem no trabalho de educar as crianças para cuidar do material, acreditando que negar-lhes o acesso é a melhor estratégia. No entanto, pelos posicionamentos registrados, há evidências de que algumas crianças já formaram um comportamento adequado para esse cuidado, como diz a Milane (8): “- Quando batesse o sinal, a gente vinha guardar de novo”. O pensamento de Hendrick (2005, p. 49) traduz bem essa postura do adulto/ profissional responsável pela gestão da escola:

Deste modo, a personalidade é sempre associada à idade adulta. Já que as crianças não são adultos, são excluídas de conjuntos de compreensões, tanto quanto é possível e desejável em relações humanas. O que quero afirmar é que os adultos não sentem que têm de investigar a natureza das suas relações com crianças, já que a compreensão delas consiste na falta de capacidade racional. Assim, facilmente se lhes nega a acção, privando-as, por isso, de direitos civis como pessoas. Isto permite que adultos ponham as crianças - os sujeitos do paternalismo - fora da definição de personalidade.

Vemos, portanto, que as crianças, como sujeitos concretos, possuem conhecimentos, desejos, opiniões próprias, que lhes possibilitam pensar a escola. Contudo, 
a postura adultocêntrica de diversos profissionais da educação lhes nega a possibilidade de atuação ativa, entendendo-as como seres sem capacidade para participar das decisões que lhes afetam ou com capacidade ainda em formação. Sendo assim, as relações que esses adultos estabelecem com as crianças é ora de indiferença ora de superproteção, acreditando que são eles que melhor definem aquilo de que as crianças necessitam. Nos eixos temáticos seguintes, é possível adentrar nas questões acima pontuadas: negação de acesso a materiais; necessidade de organização destes e postura adultocêntrica de profissionais da escola.

\section{A perspectiva do direito nas vozes das crianças}

Sarmento (2011b, p. 43) afirma que "as crianças, porque são crianças, vivem um processo de desenvolvimento que as coloca numa particular relação de dependência ante os adultos". Porém, tal dependência não significa que não devam ser reconhecidas e tratadas como sujeitos de direitos sociais; inclusive, a própria legislação lhes assegura esse reconhecimento e diversos estudos e pesquisas comprovam a sua capacidade de participação em diferentes instâncias da vida social.

É evidente que, como diz o autor, “o seu modo de interpretar e significar o mundo, sendo permeado pelas culturas nas quais se inserem, é marcado pela sua condição biopsicológica e pelo estatuto social dependente em que se encontram" (SARMENTO, 2011b, p. 43). As crianças esperam a proteção, o cuidado e a segurança que os adultos precisam lhes garantir, tanto é que em seus posicionamentos tecem críticas muito contundentes aos adultos, mas entendem que esses são imprescindíveis na organização e no funcionamento dos contextos institucionais. Assim, "nas suas relações com os adultos e nas suas relações com outras crianças, partilham, reproduzem, interpretam e modificam códigos culturais que são actualizados nesse processo interativo" (SARMENTO, 2011b, p. 44). Por mais que muitos adultos não enxerguem isso, além de reprodutoras, elas são também produtoras da cultura.

As crianças vivem um contexto histórico marcado pelo paradoxo do que delas se espera: dependência e autonomia, ambos relativizados de acordo com a conveniência dos adultos. Na escola, não é diferente. Porém, em suas interlocuções, as crianças demonstraram muita autonomia de pensamento, embora ainda demonstrem um comportamento passivo devido aos constrangimentos e às interdições que lhes impõe a governação adulta. 
As crianças têm consciência de que a merenda escolar constitui um direito delas e um dever da escola nas palavras de Flávia (10), da Escola B: “- É obrigação da escola oferecer merenda para os alunos. Tem alguns alunos que saem de casa sem merendar, tem alunos que não têm dinheiro para comprar o lanche”. Reprovam com veemência notícias que têm de escolas cujo direito não é garantido. Elas iniciam a conversa sobre a cantina atribuindo-lhe afeição, mas, ao conversarem, vão demonstrando desapontamentos em virtude do não cumprimento do cardápio, da diferenciação do que é servido nos turnos manhã e tarde (inclusive com desentendimentos sobre este ponto) e da pouca qualidade das refeições. A preferência é por carne, frango, mas o que prevalece é biscoito, pão, suco artificial, portanto, alimentos industrializados.

Por mais que as escolas afirmem que na aquisição dos produtos que compõem a merenda escolar cumprem o percentual de, no mínimo, 30\% proveniente da agricultura familiar, vê-se que, pelas narrativas das crianças, são poucos os produtos in natura oferecidos a elas, embora estejam num contexto cuja economia provém, basicamente, da agropecuária. Portanto, a formulação de políticas públicas universais, que não reconhecem as particularidades dos contextos e dos sujeitos a que se destinam, e a escassez de recursos destinados à educação como um todo no Brasil, são problemas seculares que impedem o sucesso da escolarização das crianças no país.

Barbosa, Gehlen e Fernandes (2012, p. 76) defendem a necessidade de as políticas públicas gestadas pelo Governo Federal levarem em conta a "heterogeneidade de modos de vida, da inserção nos processos produtivos e de seus universos simbólicos e as diferentes identidades socioculturais da população residente no campo". Sem atender a esse critério, essas políticas nem sempre são divulgadas e enraizadas em âmbito municipal. No caso do Programa Nacional de Alimentação Escolar (PNAE), o valor per capita disponibilizado pelo Governo Federal é tão baixo (Creche: $\mathrm{R} \$$ 1,07; Pré-escola: R\$ 0,53; Ensino Fundamental: R\$ 0,36) (MEC, 2017), que chega a inviabilizar, muitas vezes, a determinação de incrementar a merenda com produtos da agricultura familiar, fazendo com que os municípios optem por uma alimentação não saudável, como produtos industrializados, por serem mais baratos.

As crianças não podem participar nem mesmo da escolha dos produtos que lhe serão servidos na merenda escolar, mesmo que esta seja uma questão que lhes toca diretamente. Mas, como observam Sarmento, Fernandes e Tomás (2007, p. 184): “O confinamento da infância a um espaço social condicionado e controlado pelos adultos produziu, como consequência, o entendimento generalizado de que as crianças 
estão 'naturalmente' privadas do exercício de direitos políticos”. E acrescentam: "A infância é especialmente prejudicada, entre todos os grupos e categorias sociais excluídas, quer pela relativa invisibilidade face às políticas públicas e aos seus efeitos, quer porque é geralmente excluída do processo de decisão na vida colectiva" (SARMENTO; FERNANDES; TOMÁS, 2007, p. 183).

É visível esse processo de exclusão das crianças e indiferença aos seus pontos de vista. A escola, como instituição dedicada às crianças, poderia ser, antes de tudo, um espaço/tempo de formação humana e cidadã. Tolher as crianças de participar, de ser consultada e de expressar pensamentos é negar-lhe o direito à cidadania. Além da merenda escolar, outras situações provocaram indignação das crianças em relação a esse aspecto do direito, como jogos que ficam trancados em armários e, com os quais elas não podem brincar.

Desconfiamos que a natureza questionadora das crianças desestabiliza as certezas de muitos adultos, que as afastam de qualquer possibilidade de emitirem opiniões sobre o funcionamento institucional. Hendrick (2005, p. 48) enfatiza que apenas a superação da mentalidade do adultismo possibilitará "ouvir um conjunto mais autêntico e, provavelmente, mais inquietante de vozes - porque haverá certamente muitas ocasiões em que as crianças contestam e contradizem as nossas visões". Por outro lado, alguns professores aguçam a criticidade das crianças ao compartilhar com elas situações constrangedoras a que são submetidos, mostrando dificuldades de acesso a materiais importantes do ponto de vista pedagógico. Assim, as crianças refletem e concluem que elas também são constrangidas pelos obstáculos que são colocados para que tenham acesso a brinquedos, jogos, por exemplo.

Ao analisar diversas posições de teóricos sobre a participação política das crianças, Qvortrup (2010b, p. 779) questiona: "Deveríamos fazer de tudo para proteger as crianças ao preço de deixá-las fora da 'sociedade' ou deveríamos reconhecê-las como pessoas, participantes, cidadãs com o risco de expô-las às forças econômicas, políticas, sexuais [...]?". Continuamos defendendo que o confinamento das crianças em instituições não deve mais servir para segregá-las, tirando-lhes o direito a exercer o papel de ator social, como aconteceu nos primórdios da escola de massas. Corroboramos, portanto, o pensamento de Qvortrup (2010b, p. 779-780): "De fato, ninguém está disposto a sacrificar a necessária proteção das crianças expondo-as a todos os riscos de uma sociedade moderna; porém, ninguém concordaria em privar as crianças de se experimentarem como pessoas que contribuem para a sociedade”. 
Oportunidades de pesquisa tendo as crianças como coparticipantes demonstram que não há motivos para se negar tal experimentação, pois as crianças constituem um coletivo que pensa os espaços institucionais com bom senso e criticidade. As crianças têm discernimento suficiente em diversas questões e conseguem, no coletivo, lançar um olhar escrutinador, sensível e crítico para diversas dimensões do ambiente escolar, já que este é fonte de experiências cotidianas que as constitui como pessoas inseridas socialmente.

\section{0 espaço micro da sala de aula}

A sala de aula é o espaço escolar dentro do qual as crianças passam a maior parte do tempo em que permanecem na escola. Petschen (apud BENITO, 2017, p. 33) considera que os estudos sobre as instituições escolares deveriam destinar maior atenção a esse microcontexto, que ele define como uma mescla de "lógica, magia, drama e retórica". Realmente, nos momentos em que conversávamos sobre as aulas, as crianças explicitaram muitos aspectos que merecem uma detida reflexão, em narrativas densas, carregadas de afetos em relação às práticas dos professores, aos componentes curriculares, ao conhecimento, às relações com os pares.

Diversos elementos podem ser retirados para análise da escola na perspectiva das crianças, o que vai ao encontro das recomendações de Benito (2017, p. 35): acontecimentos triviais que se sucedem durante as aulas permitem compreender a escola, pois "sob essas banalidades, subjaz não apenas um sistema estruturado de sociabilidade, mas toda uma cultura". Como agentes produtores dessa cultura, junto a seus professores e professoras, as crianças nos permitiram uma visão privilegiada da sala de aula, ao voltarem seus olhares para os sujeitos, os objetos e as ações, categorias fundamentais.

Apesar das contradições apontadas ao falarem sobre a escola, elas demonstraram, em diversos momentos das interações nos grupos focais, compreenderem $o$ papel desta instituição, considerando-a importante para sua formação, como espaço de acesso ao conhecimento, mas também de socialização, como disserta Marília (10), da Escola B: “- A melhor coisa do mundo é a escola, porque a gente aprende mais coisas, a ler, a respeitar, a educar. Tipo quem quer ser professora aprende a ser professora”. Essa ênfase na formação profissional foi reiterada também por Murilo (9), da Escola A: “- Meu sonho é estudar para ser veterinário”. As crianças, portanto, têm sonhos para o futuro que esperam que a escola possa contribuir para sua consecução. 
Outro aspecto ressaltado é a amizade com professores e com seus pares (André (8): “- $O$ que eu mais gosto é de ficar aqui junto com meus colegas e com meus professores."), embora destaquem também afetos negativos em relação a alguns. Ao tempo em que elogiam o tratamento atencioso e carinhoso que recebem de alguns professores, algumas crianças também reprovam atitudes de outros docentes, principalmente porque brigam muito em sala de aula com os alunos. O professor legal, na concepção das crianças, é aquele que sabe explicar os conteúdos, que propõe atividades mais lúdicas, com jogos, desenho, pintura, etc., e, claro, que "sabe respeitar os alunos", como diz Flávia (10). Gallego e Silva (2011, p. 43) lembram "que os alunos produzem avaliações sobre os professores e informalmente, com frequência, associam características pessoais, como responsabilidade, paciência, dedicação, empenho etc., a competências 'técnicas', como o conhecimento ou a atualização".

As aulas de Artes foram muito citadas pelas crianças como as preferidas, e as práticas tradicionais de cópia e de memorização foram bastante criticadas por elas. Oliveira-Formosinho (2007, p. 13) alerta para propostas que "criam alguma ressonância ao nível da retórica da política educativa, [mas que] nunca conseguiram penetrar a carapaça burocrática que protege a pedagogia tradicional, ou seja, nunca conseguiram transformar a esfera praxiológica".

As crianças questionam práticas docentes que se resumem a escrever no quadro, outras que os deixam ociosos depois que concluem a tarefa solicitada. Queriam mais inovações nas aulas para não ficar sem fazer nada: "brinquedos, jogos, livros". Oliveira-Formosinho (2007, p. 13) denuncia "a persistência de um modo de fazer pedagógico que ignora os direitos da criança a ser vista como competente e a ter espaço de participação (o modo pedagógico transmissivo ou a pedagogia transmissiva), não por falta de pensamento e propostas alternativas”. É preciso problematizar as práticas para que sejam transformadas numa perspectiva que contemple as crianças, seus desejos, anseios, necessidades e potencialidades, além de seus direitos.

As próprias crianças, em suas interlocuções, dão ideias de como mobilizar os alunos nas aulas: Flávia (10): “- Eu queria que tivesse mais aulas-passeio para o Monumento do Jenipapo, Museu, Zoológico, Parque. Tinha uma professora aqui que fazia jogos, brincadeiras, era bom demais”; Jeane (9): “- As professoras não levam mais livros infantis para as salas, porque pensam que a gente não é mais criança; Ravi (9): “- Os professores levam só o livro, pincel, caneta e estilete. Passa a atividade do livro ou para escrever no caderno. Às vezes escreve muito no quadro. Era bom se tivesse aula-passeio. Seria bom ir para o zoológico". 
Um aspecto positivo, conectado com as necessidades das crianças, é o dia de jogos educativos, citado por Amália (9), da Escola A. Cumpre destacar que a Educação em Tempo Integral, que tem lugar na Escola B, vai em direção desse caráter mais lúdico, pois as crianças têm a oportunidade de desenvolverem outros tipos de atividades que não sejam apenas focadas no cognitivo. Na Escola A, as crianças sentem saudade do tempo em que esse Programa Federal foi implantado na escola, como enfatiza Vívian (8), em outro momento do grupo focal sobre a escola: "- Tia, para melhorar, poderia ter aula em que todos podem participar. Tinha aula de balé na escola e só podia participar as meninas. E futebol para meninos. Capoeira para meninos e meninas. Já teve, mas não tem mais. Quando acabou o ano, os professores não vieram mais".

Há aspectos universais que caracterizam o ser criança, conforme Sarmento (2003): a fantasia, a criatividade, a interatividade, a ludicidade. Por isso, a novidade as fascina, e a escola deveria considerar isso ao organizar seus espaços, tempos, atividades pedagógicas. Em suas falas, as crianças deixam clara a necessidade de propostas mais desafiadoras e lúdicas, inclusive imaginando cenários para o ambiente escolar tomando por base escolas vistas em programas televisivos, como retrata Flávia (10), da Escola B, em uma de suas falas: “- Meu sonho é estudar numa escola que tivesse freira, um quarto para a gente dormir, tinha aula de músi$c a$, jogos,...”. Mediadora estranha e questiona: “- Freira?”. Ao que ela responde firmemente: “- Sim”. E Jeane (9) ajuda a explicar: “- É que nem a da novela Carinha de Anjo, né Flávia?”.

Na contemporaneidade, é inegável a transformação dos cotidianos das crianças por efeito dos meios de comunicação e informação. As crianças da Escola A também narram seus desejos de terem acesso a inovações tecnológicas, como sugere Tadeu (8): “- Sabe qual é meu sonho? Meu sonho é que a escola coloque internet, que a gente use as tecnologias para estudar". O sonho da criança nos remete à observação de Sarmento (2011a, p. 595) de que, atualmente, a escola "é compungida a incorporar as tecnologias de informação e comunicação no seu programa institucional, procurando evitar a desvalorização do seu capital simbólico".

A própria atividade de pesquisa comprova a atração das crianças pela novidade. Elas demonstraram muita satisfação em fotografar espaços, dar suas opiniões, expressar seus pontos de vista e desenhar. Em suas falas deixam transparecer, com nitidez, que desenhar é uma atividade muito prazerosa e, falar dos desenhos, ao mesmo tempo em que causa timidez em algumas crianças, todas exprimem felicidade por expressarem suas ideias. 
As crianças da Escola A reiteram, ainda, em suas narrativas, problemas que atrapalham a aprendizagem, como a falta de condições materiais das salas de aula e a indisciplina de alguns de seus pares, como André (8) relata: “- Tia, o quadro da sala está manchado, poderia mudar para melhorar as aulas e o ventilador não presta, e o armário está todo quebrado. Eu também não gosto quando meninos ficam pulando a janela da escola. Tem vezes que a professora briga e bota para a diretoria”. Esta situação é reforçada por Murilo (9): “- Uma coisa que eu não gosto também é da bagunça. Tem uns meninos que jogam cadeiras no chão. $E$ os professores e o diretor não fazem nada".

A indisciplina de colegas é muito recorrente nas falas das crianças, nas duas escolas, a ponto de Danilo (8), da Escola A, dizer que o que menos gosta nas aulas é de um colega, que "é muito atentado e fica caçando conversa o tempo todo", sugerindo, inclusive, que ele seja tirado da sala de aula para melhorar as aulas. E na Escola B, Flávia (10) relata: "- Professora, têm alunos que brigam na sala e a professora fica sorrindo". Também Jeane (9) demonstra incômodo com esse tipo de comportamento de alguns colegas durante as aulas: "- Os meninos poderiam fazer menos barulho, jogar os papeis no lixo. Às vezes, a tia está escrevendo e os meninos jogam a atividade no lixo. A tia manda eles escreverem de novo".

As crianças externam representações sociais do que seja o mau e o bom aluno, sendo este último aquele que se adequa às normas institucionais. Gallego e Silva (2011, p. 34-35) chamam a atenção para problemas recorrentes nas aulas, derivados da cristalização de práticas incorporadas do ensino simultâneo instituído no final do século XIX no Brasil, que tentam homogeneizar o que é diverso:

Cópias, ditados, leituras, exercícios sempre para todos da turma e a serem feitos ao mesmo tempo no mesmo ritmo! Quem não consegue é lento, portanto atrapalha. Quem vai rápido demais, também atrapalha! O ideal é ao mesmo tempo, sem momentos vazios e ociosos, pois o término antecipado gera bagunça e os lentos promovem igualmente a desordem! Ao passar por isso como alunos é esse modelo que incorporamos e nos serve de referência quando assumimos a profissão docente.

As crianças consideram que as relações interpessoais no ambiente escolar devem ser trabalhadas para que se tornem melhores, e esperam que os adultos assumam a função de intervir para proporcionar essa melhoria. Chamamos a atenção, ainda, para uma fala de Tadeu (9), da Escola A: “- Eu queria que as salas fossem maiores e não precisasse os alunos serem transferidos para outras escolas”. Inclusive, em seu desenho da escola, ele produziu uma arte na qual esta instituição era 
muito grande e, ao falar sobre seu desenho, ele disse: “- Nessa escola, cabem cinco mil alunos, para que nunca os alunos tenham que mudar de escola”.

Delalande (2011, p. 73), em suas pesquisas sobre a escola, tendo crianças como interlocutoras, também detecta, por parte dessas, "uma impaciência ao deixar uma escola e um grupo de crianças que se conhecem muito bem, associado ao medo do desconhecido e dos grandes colégios". É, portanto, importante que a escola pense em estratégias para que essa transição de uma escola para outra seja mais tranquila. A autora francesa, com base nessa dificuldade apresentada pelas crianças, associou a pesquisa à realização de uma oficina, cujo objetivo foi realizar um pequeno jornal a ser divulgado entre os alunos do último ano de uma escola e os da outra escola, que estudavam na série em que aqueles ingressariam no ano seguinte, "a fim de que os primeiros se beneficiem dos testemunhos de seus predecessores e que os alunos jovens do colégio constatem que eles vivem, uns e outros, emoções e acontecimentos comuns em torno da sua iniciação ao colégio" (DELALANDE, 2011, p. 75).

Diante das análises dos eixos temáticos, reafirmamos a importância de se olhar para as possibilidades de ação das crianças, planejando, no coletivo, formas de considerá-las no contexto da prática pedagógica. Caldart (2015) esclarece que a luta do movimento de Educação do Campo deve ser por uma escola comprometida com as crianças e com as suas experiências e aprendizados, o que alarga a visão sobre o papel formativo desta instituição educativa. No entanto, as análises aqui apresentadas colocam-nos diversos desafios no sentido de materializar os princípios da Educação do Campo e os pressupostos da Sociologia da Infância, em defesa de uma escola no/do campo que respeite e reconheça, em suas práticas, os direitos das crianças.

\section{Considerações finais}

A discussão em torno dos sentidos produzidos pelas crianças camponesas sobre a escola do campo revelou a capacidade que possuem para analisar o contexto institucional, apontando contradições e propondo estratégias de melhoria das práticas que nele se desenvolvem. É possível afirmar que, se as crianças forem ouvidas com respeito e atenção, poderão contribuir de modo significativo para fortalecer a instituição escolar como espaço de formação humana, de aprendizagem e de desenvolvimento do protagonismo infantil. Assim, é preciso redefinir os papeis atribuídos às crianças e por elas assumidos, no bojo da escola e das práticas docentes. 
As análises empreendidas revelaram que, na escola, ainda estão cristalizados pensamentos e práticas que traduzem uma concepção de criança como ser da falta, da incapacidade, por isso lhes são interditados a atuação ativa, o exercício da cidadania, dentro das possibilidades que possuem. No entanto, ao pensarem a escola, demonstraram firmeza em seus posicionamentos em relação à forma como os espaços e materiais estão organizados, que afetam diretamente no tipo de relações que são construídas e vivenciadas. Além disso, evidenciaram que têm consciência do que lhes é de direito e que, porém, lhes é negado.

Nesse sentido, o estudo comprovou o potencial que as crianças possuem para a participação social, no sentido de serem efetivamente inseridas em instâncias decisórias na escola, sendo urgente o reposicionamento delas como sujeitos que pensam e contribuem para a (re)construção do ambiente educativo.

\section{Referências}

BARBOSA, M. C. S.; GEHLEN, I.; FERNANDES, S. B. A oferta e a demanda de Educação Infantil no campo: um estudo a partir de dados primários. In: BARBOSA, M. C. S. et al. (Coord.). Oferta e demanda de Educação Infantil no campo. Porto Alegre: Evangraf, 2012.

BENITO, A. E. A escola como cultura: experiência, memória e arqueologia. (Trad. Heloísa Helena Pimenta Rocha e Vera Lucia Gaspar da Silva). Campinas, SP: Alínea, 2017.

BRASIL. Lei n. 9.394, de 20 de dezembro de 1996. Estabelece as diretrizes e bases da educação nacional. Brasília, dez. 1996. Disponível em: http://www.planalto.gov.br/ccivil_03/leis/L9394. htm. Acesso em: 28 fev. 2019.

CALDART, R. S. Sobre a especificidade da Educação do Campo e os desafios do momento atual. 2015. Disponível em: https://sigaa.ufpa.br/sigaa/verProducao?idProducao=280289\&key=072c077c4aef39fe4f804ac7eeb654bc. Acesso em: 14 jan. 2019.

CLANDININ, D. J.; CONNELLY, F. M. Pesquisa Narrativa: experiência e história em pesquisa qualitativa. 2. ed rev. Uberlândia: EDUFU, 2015.

DELALANDE, J. As crianças na escola: pesquisas antropológicas. In. MARTINS FILHO, A. J.; PRADO, P. D. (org.). Das pesquisas com crianças à complexidade da infância. Campinas, SP: Autores Associados, 2011.

DELGADO, A. C. C.; MULLER, F. Infâncias, tempos e espaços: um diálogo com Manuel Jacinto Sarmento. Currículo sem Fronteiras, v. 6, n. 1, jan./jun. 2006, p. 15-24. Disponível em: http:// www.curriculosemfronteiras.org/vol6isslarticles/sarmento.pdf. Acesso em: 12 jul. 2017.

GALLEGO, R. de C.; SILVA, V. B. da. A gestão do tempo e do espaço na escola: Módulo 4 (Curso RedeFor de Gestão da Escola para Diretores). São Paulo: Secretaria de Educação do Estado de São Paulo/Universidade de São Paulo, 2011. 
GATTI, B. A. Grupo focal na pesquisa em ciências sociais e humanas. Brasília: Liber Livro Editora, 2005.

GONDRA, J. G. A emergência da escola. São Paulo: Cortez, 2018.

GOUVÊA, M. C. S. Infantia: entre a anterioridade e a alteridade. Edu. Real., Porto Alegre, v. 36, n. 2, maio/ago. 2011, p. 547-567. ISSN: 2175-6236. Disponível em: http://www.ufrgs.br/ edu_realidade. Acesso em: 05 out. 2014.

HENDRICK, H. A criança como actor social em fontes históricas: problemas de identificação e interpretação. In. CHRISTENSEN, Pia; JAMES, Allison. Investigação com crianças: perspectivas e práticas. Porto: Ediliber Editora de Publicações, 2005.

LEAL, F. de L. A.; RAMOS, F. Educação Infantil do Campo em foco: infraestrutura e proposta pedagógica em escolas do Nordeste. In. BARBOSA, M. C. S. et al. (Coord.). Oferta e demanda de educação infantil no campo. Porto Alegre: Evangraf, 2012.

MEC. Ministério da Educação. PNAE - Programa Nacional de Alimentação Escolar. Brasília, 2017. Disponível em: https://www.fnde.gov.br/index.php/programas/pnae. Acesso em: 23 jul. 2018.

OLIVEIRA-FORMOSINHO, J. Pedagogia(s) da infância: reconstruindo uma práxis de participação. In. OLIVEIRA-FORMOSINHO, J.; KISHIMOTO, T. M.; PINAZZA, M. A. (org.). Pedagogia(s) da infância: dialogando com o passado e construindo o futuro. Porto Alegre: Artmed, 2007.

PASSEGGI, M.; NASCIMENTO, G.; OLIVEIRA, R. de. As narrativas autobiográficas como fonte e método de pesquisa qualitativa em Educação. Revista Lusófona de Educação, n. 33, 2016, p. 111-125.

QVORTRUP, J. Infância e política. Cadernos de Pesquisa, v.40, n.141, set./dez. 2010. p. 777-792.

RAMOS, J. F. P.; LEITE, A. A.; FILGUEIRAS FILHO, L. de A. Função social da escola: qual o lugar do pedagógico, do político e do trabalho? 2012. Disponível em: http://educas.com.br/blog/ wp-content/uploads/2012/04/FUN\%C3\%87\%C3\%83O-SOCIAL-DA-ESCOLA.pdf. Acesso em: 26 fev. 2019.

SARMENTO, M. J.; FERNANDES, N.; TOMÁS, C. Políticas públicas e participação infantil. Educação, sociedade e culturas, n. 25, 2007, p. 183-206.

SARMENTO, M. J. As culturas da infância nas encruzilhadas da $2^{\underline{a}}$ modernidade. Braga: Instituto de Estudos da Criança, Universidade do Minho, 2003. (Texto digitado).

SARMENTO, M. J. A reinvenção do ofício de criança e de aluno. Atos de Pesquisa em Educação, v. 6 , n. 3, set./dez. 2011a. p. 581-602.

SARMENTO, M. J. Conhecer a infância: os desenhos das crianças como produções simbólicas. In. MARTINS FILHO, Altino José; PRADO, Patrícia Dias (org.). Das pesquisas com crianças à complexidade da infância. Campinas, SP: Autores Associados, 2011b.

SARMENTO, M. J. Gerações e alteridade: interrogações a partir da sociologia da infância. Educ. Soc., Campinas, v. 26, n. 91, maio/ago. 2005. p. 361-378. 
SIBILIA, P. Redes ou paredes: a escola em tempos de dispersão. Trad. Vera Ribeiro. Rio de Janeiro: Contraponto, 2012.

SILVA, I. de O. e; LUZ, I. R. da. Espaços, ambientes e contextos: reflexões sobre a educação infantil para crianças de 0 a 6 anos residentes em área rural em dois municípios da região sudeste do Brasil. In: BARBOSA, M. C. S. et al. (Coord.). Oferta e demanda de educação infantil no campo. Porto Alegre: Evangraf, 2012.

TELLEZ, G. A. M. Espaço-escolar e sistema-mundial: análise das recomendações da Unesco-ONU para a América Latina. 2017. 269f. Tese (Doutorado em Educação) - Programa de Pós-Graduação em Educação: Universidade Federal de Uberlândia, Uberlândia/MG, 2017.

VARELA, J.; ALVAREZ-URIA, F. A maquinaria escolar. Teoria \& Educação. São Paulo, n. 6, p. 68-96, 1992. 